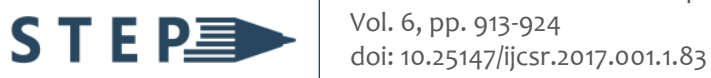 \\ https://stepacademic.net
}

\section{Short Paper* \\ An Agile Prototyping Approach on the Design of the Purchase Request and Financial Tracking System}

\author{
Mark Van M. Buladaco \\ Institute of Information Technology, Davao del Norte State College, Philippines \\ markvan.buladaco@dnsc.edu.ph \\ (corresponding author) \\ Jennifer E. Sabugaa \\ College of Computing and Information Sciences, Caraga State University, Philippines \\ jesabugaa@carsu.edu.ph
}

Date received: November 15, 2021

Date received in revised form: January 17, 2022

Date accepted: January 17, 2022

Recommended citation:

Buladaco, M. V., \& Sabugaa, J. (2022). An agile prototyping approach on the design of the purchase request and financial tracking system. International Journal of Computing Sciences Research, 6, 913-924. doi: 10.25147/ijcsr.2017.001.1.83.

*Special Issue on National Research Conference in Computer Engineering and Technology 2021. Guest Editor: Dr. Luisito Lolong Lacatan, PCpE (Laguna University, Philippines). Associate Editors: Dr. Nelson C. Rodelas, PCpE (University of the East-Caloocan City, Philippines), and Engr. Ana Antoniette C. Illahi, PCpE (De La Salle University, Manila, Philippines).

\section{Abstract}

Purpose - This paper focuses on designing a purchase request and financial tracking system to better support the government agencies in fast, easy management and better understand a more comprehensive strategy for its financial activities.

Method - It employs an agile prototyping approach for fast and cost-effective turnaround. UML approach was utilized for designing process models and data models.

Results - The prototypes allow you to observe real user behavior as they interact with your design and obtain detailed feedback about your designs, alternatives, and ideas 
before implementing them. Various process and data models are designed and presented in this paper with exact and comprehend steps for the programmers to follow during the software development life cycle (SDLC).

Conclusion - Making the developed models as the government's guide in engaging and embracing emerging technological innovations would impact the purchase request processes and financial tracking management quality. These models will certainly provide new knowledge, theories, and methods for the experts who will put these prints into action or implementation and other researchers who wish to seek facts relevant to purchase requests and financial tracking of government transactions.

Recommendations - It is recommended to utilize this design to develop the software in a purchase request and financial tracking in government agencies in the Philippines. It is also recommended to consider adding PR Mapping; aside from tracking the PR through status, they could suggest adding the PR mapping to track the PR, upload other documents that require in their purchase request, and adding machine learning algorithms to predict the budget allocation of each office for the next incoming years.

Research Implications - This paper's results will eventually be significant in the development of a purchase request system for different government agencies in the Philippines.

Keywords - Purchase Request, Financial Tracking, Agile Prototyping, Philippines

\section{INTRODUCTION}

Like the financial service industry and government agencies, several industries benefit from rapid and uprising technology innovations. The product of these innovations is utilized to the best advantage in providing swift and reliable service not just to the company or the organization but to the people whom the company serves as well (Office of Technology Assessment, 1984). Through technology applications, multiple organizations can provide the general public with modern, technology-based, and efficient services that are more diverse but effective than those in the past.

In the government, purchasing involves the acquisition of goods and services obtained to sustain its everyday activity (Vicente, 2008) and deliver its known services at the right time. By definition, a purchase request is a request from a department or officer to the procurement area for purchasing specific goods, items, goods, and services (Office of Research University of Michigan Medical School, 2020). It would make sense for the government to spend time on purchase requests to influence buy quality (Salcedo, 2016). 
On the other hand, financial tracking monitors and records the government's office budget allocation and expenses. A new tracking budget approach is essential for a better understanding of the behavior toward a more inclusive strategy to address its core activities (Jose, 2012).

However, there is a prevalent impression that governments are resistant to change and innovations (Ritchie, 2014) and opt to use the traditional ways of processing purchase requests and even tracking their financial transactions. These agencies are suffering from the following difficulties: the use of Microsoft office applications in producing purchase requests, the prolonged process of purchasing and disbursement, and the drawn-out process of financial transaction tracking. Salcedo (2016) concluded that the item acquisition process's bottleneck is the purchase request since it tends to get stuck due to a lack of analysis and methodologies. The same is true in dealing with financial management, which created several schools' difficulties (Naidoo, 2010) and other government agencies.

This paper's main objective is to design a purchase request and financial tracking system utilizing an agile prototyping approach. This paper also analyzes the system process by producing process models and data models. The Purchase Request and Financial Tracking System design will help the organization easily manage purchase requests, fast-tracking financial transactions, fast-generation files, and other reports. The authors identified apparent knowledge, theoretical, and methodological gaps because of the absence of published literature relative to the design of a Purchase Request and Financial Tracking System. In this study, the seek to establish new inquiries and insights by designing a Purchase Request and Tracking System for government agencies, using the Agile Prototyping Approach; this is significant for the government agencies to have a baseline for automation and computerization, thereby addressing the mentioned gaps in knowledge, theories, and methods.

\section{LITERATURE REVIEW}

\section{Related Systems}

The Financial Advisory System from Financial Engines Inc. in the United States, for example, gives some advice to the user regarding feasible and optimal portfolio allocations among a set of available financial products (Jones C. L. et al. 1997). In this way, the expected returns and correlations of a plurality of financial products are generated, and portfolios are optimized.

Another system called Centralized File Movement and Tracking Information System (CeFMaTIS) was developed for tertiary institutions in Nigeria, track files, and replace the manual record-keeping system for files/letters with a more efficient paperless automated system (Omoregbe et al. 2014). 
The Disaster Risk Management and Financing System in the Philippines, on the other hand, forecasts the impact of disaster mitigation and automates signaled and applied disaster financing. Mitigation means based on location-dependent natural disaster impacts (Buamgartner et al. 2016).

\section{METHODOLOGY}

\section{System Development Method}

The development of the purchase request and financial tracking system will employ an agile prototyping approach. In the agile prototyping approach, a version of (parts of) your design with just enough functionality to compare design alternatives and test the unknowns and the design's riskier elements (Jones and Richey, 2000). It is produced using rapid-prototyping tools for a fast and cost-effective turnaround. The prototypes allow you to observe real user behavior as they interact with your design and to obtain detailed feedback about your designs, alternatives, and ideas before implementing them.

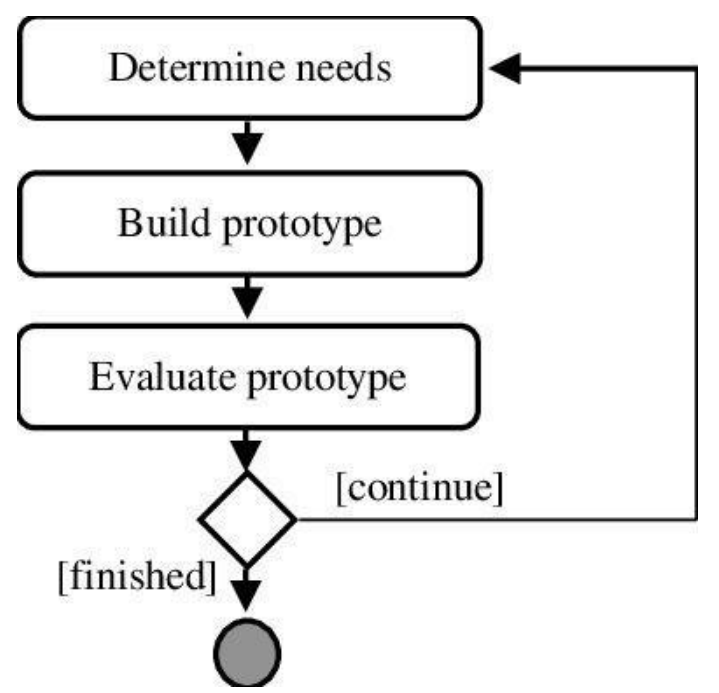

Figure 1. Agile Prototyping Model

This paper will utilize the agile prototyping model to implement an online air monitoring system for selected areas in Valenzuela City (Espinoza et al., 2018). Figure 1 shows the iteration phases in each prototype, which involve determining needs, building a prototype, and evaluating the prototype. These phases will be repeated until such time the user will accept the final prototype. Software prototyping is the movement of making models of programming or software applications, i.e., inadequate variants of the created product program. In this paper, rapid Prototyping will be released in each iteration based on the agile prototyping model in figure 1. Rapid Prototyping applies an iterative way to deal with the planning phase of an application or website (Jones \& Richey, 2000). The goal is to rapidly improve the plan utilizing routinely refreshed models and different short cycles. 


\section{UML Methods}

Unified Modelling Language (UML) methods are used for the system's process modeling and data modeling. The UML approach is well worth examining and understanding because of its wide acknowledgment and use. UML gives a normalized set of devices to report a software framework's investigation and plan (Waykar, 2013). Case study approaches are employed in conducting the system's design, especially in the iteration of the prototype.

\section{RESULTS}

\section{Purchase Request Process}

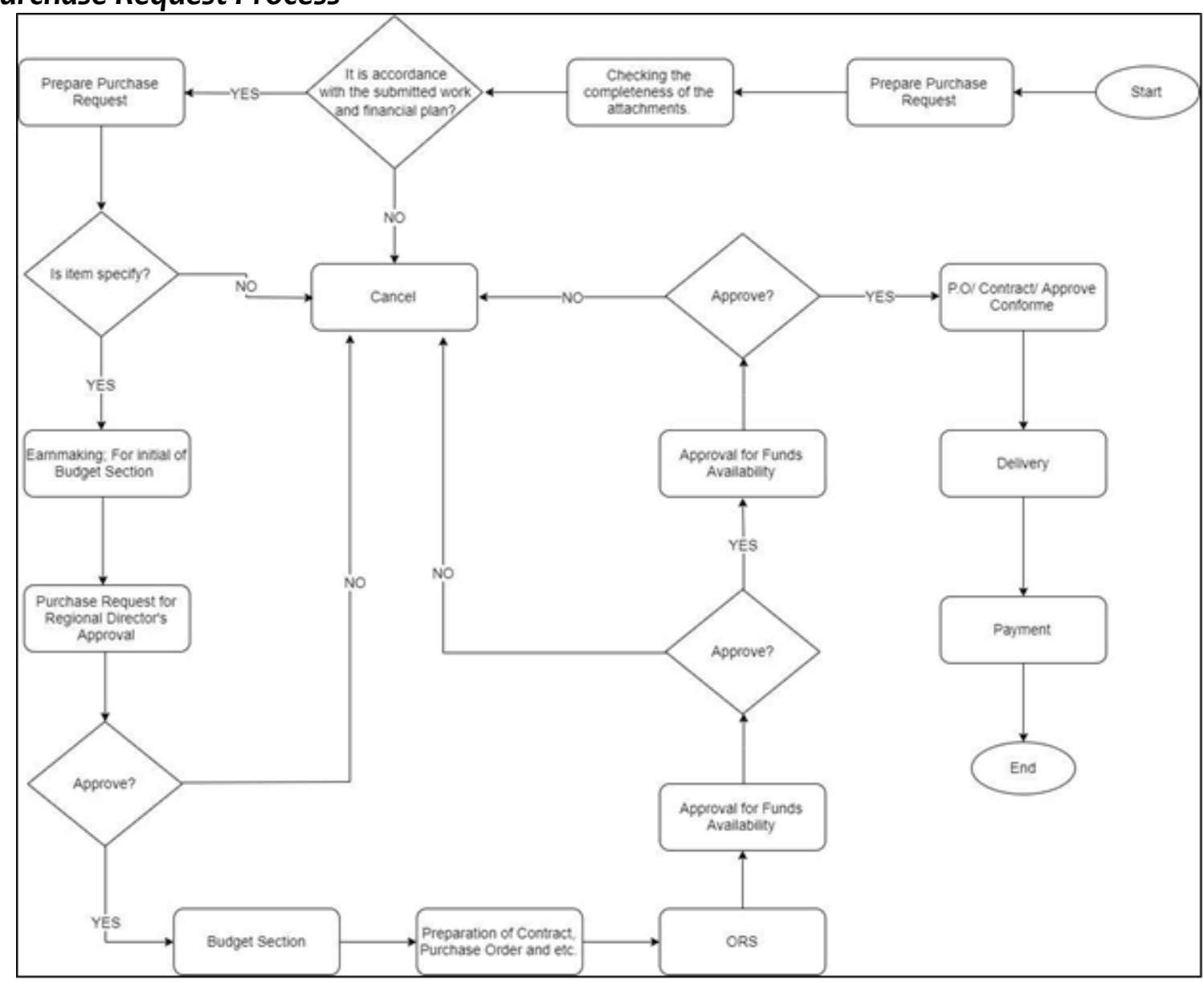

Figure 2. Purchase request process in government agencies

Figure 2 shows the purchase request process in government agencies. The process lets the end-users prepare their purchase request order. If the end-users meet the desired papers and attachments, turn complete, the process will proceed too. Once submitted, the requisition must route to any or all financial and director's officers for approval and people the individual who is accountable for the financial transactions of a specific 
account. Once approved, the requisition will attend the Contract Manager assignment (Purchasing Staff). On the opposite hand, if a money handler disapproves of a requisition, a notification is routed back to any or all previous approvers and, therefore, the initiator as an FYl. Note that the requisition routes to a treasurer at a minimum should route to more people counting on rules founded by units and information provided within the requisition.

\section{Process Models}

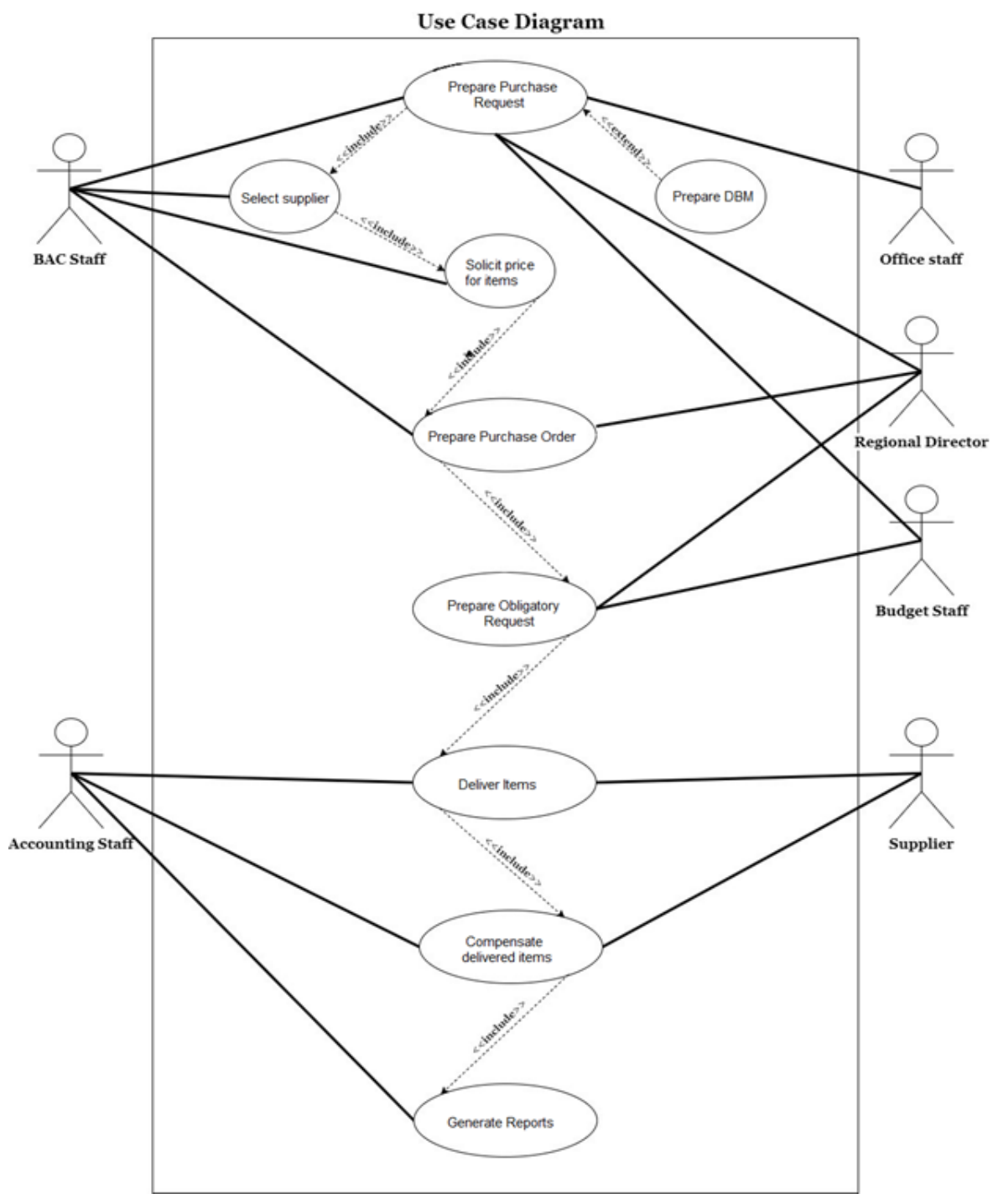

Figure 3. Use Case Diagram

In understanding the design of the purchase request and financial tracking system, figure 3 shows the use case diagram. The main functions of use case diagrams are to collect a system's requirements with internal and external influences (Dennis et al., 2012). 
These requirements are mostly design requirements. So, when a system is evaluated to gather its functionalities use, cases should presently be able, and actors are identified. The diagram above shows the relationship between BAC staff, office staff, regional director, and budget staff; they serve as the systems' users. It describes the flow of the system in different users, and it also portrays the sequence of actions of the system that provides interaction with other actors of the system.

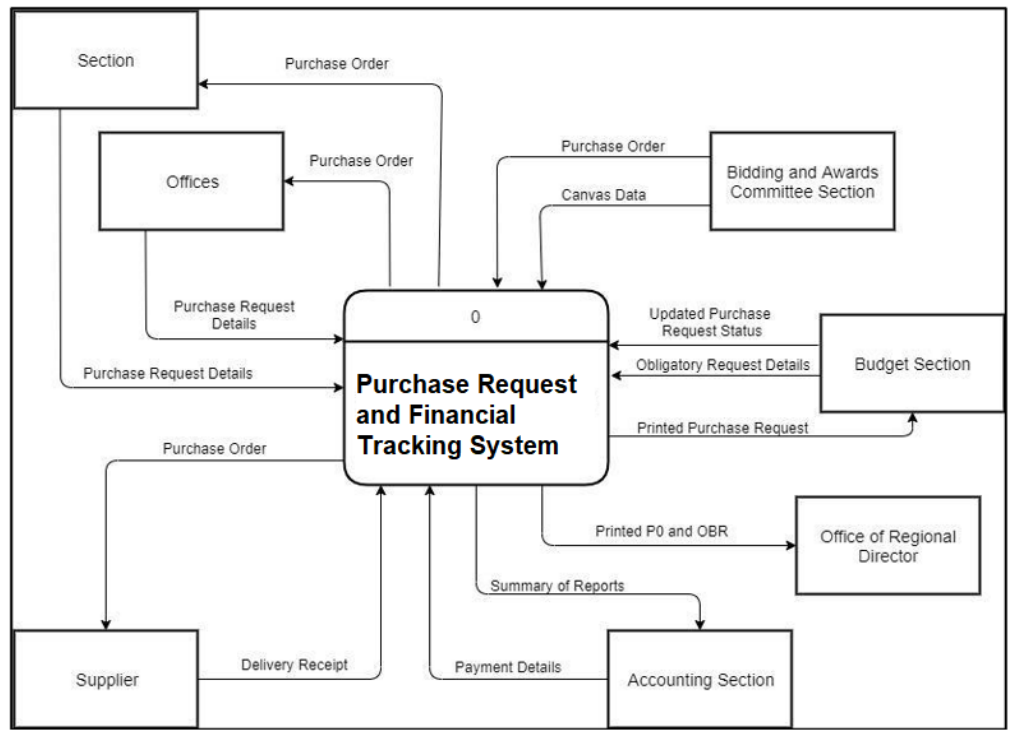

Figure 4. Context Data Flow Diagram

Figure 4 shows a context diagram that defines the system's boundary, the setting, and the objects that interact with it. It shows the individual that provides data into the system. The Purchase Request and Financial Tracking System processed commodities in acquiring requests and orders. It is also stored in the system related to finances to generate reports. The system provides a heat map of commodities which the data come from different sections of a certain government agency. By its functionalities, the agency can populate the data that was enumerated into the system.

As Figure 5 shows, the level o data flow diagram above all the major processes that comprise the overall system, the internal and external components of process 0 . It displays the major processes that are interrelated by data flows and views with which they interact. As the figure flows, a level o context diagram can be exploded into a level 1 DFD. The same process can be applied to each process appearing within other levels of DFD. According to Dennis et al. (2012), every data flow into and out of the parent process must appear as part of the child DFD. 


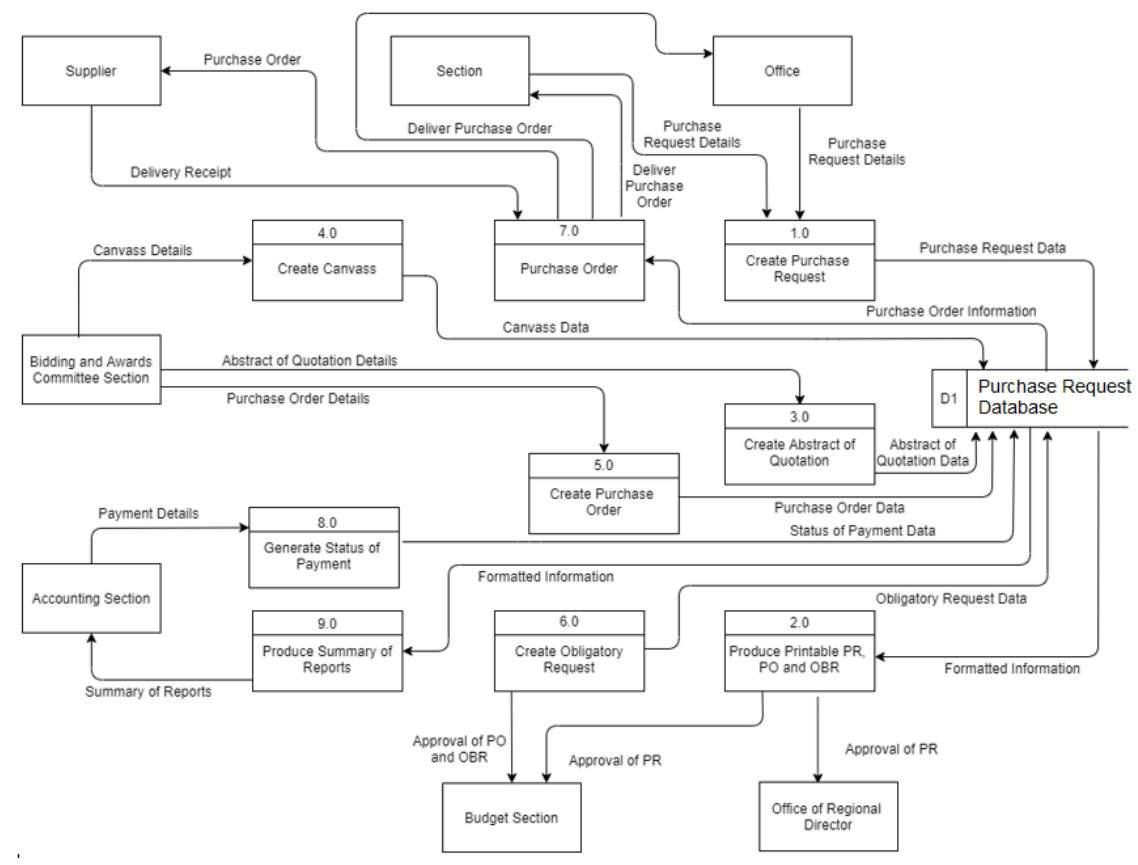

Figure 5. Level o data flow diagram

\section{Data Model}

Figure 6 shows the relationship between the different classes of the system. This diagram determines the process and functions that were relevant to the system. A class diagram was used to describe the system's structure by showing its classes, attributes, and operations. It was generated from the Entity Relationship Diagram. The ERD symbolizes the conceptual database as seen by the end-user. ERDs represent the database's main components: entities, attributes, and relationships. The ERD is that the modeling tools are accustomed to developing can also form successful database design and implementation (Elmasri and Navathe, 2011). Chen's notation favors conceptual modeling. At the same time, the Crow's Foot notation favors a more implementationoriented approach. Lastly, the UML notation will be used for both conceptual and implementation modeling. 


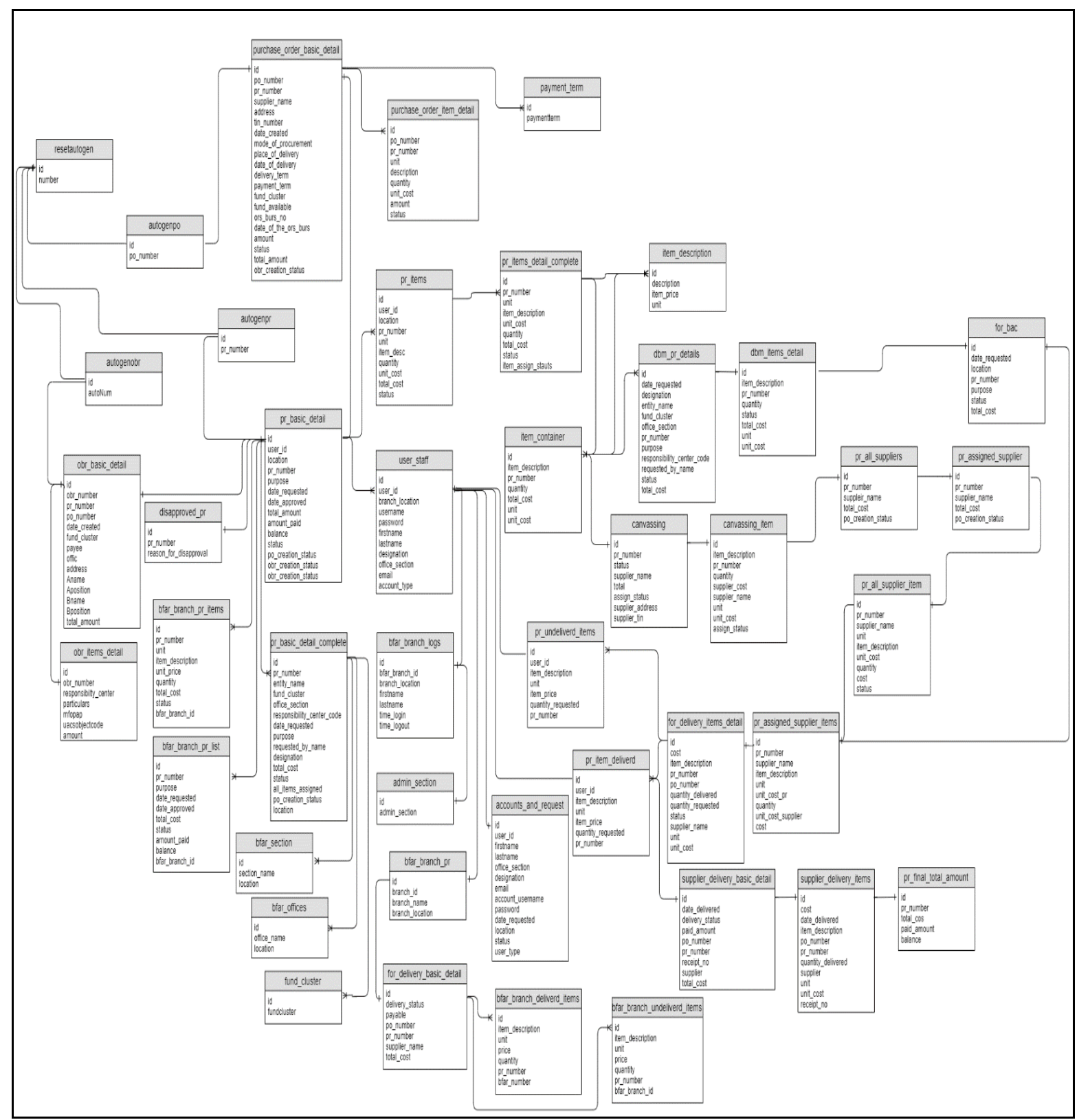

Figure 6. Entity Relationship Diagram

\section{DISCUSSION}

An agile prototyping approach to the design of a purchase request and financial monitoring system will simplify and speed up the administration of purchases and financial tracking. Government procurement procedures and financial monitoring management would be negatively impacted if the government relied on established approaches for engaging and accepting new technology advancements.

Data flow, context, use case, and entity-relationship diagrams have all been created as part of the development process. There is little doubt that the professionals 
who will deploy these models and other scholars who are interested in government procurement and financial monitoring will get fresh insights from these models.

\section{CONCLUSIONS AND RECOMMENDATIONS}

The design of purchase request and financial tracking system employed with an agile prototyping approach will make the management of purchases and financial tracking easier and faster. Making the developed models as the government's guide in engaging and embracing emerging technological innovations would impact the purchase request processes and financial tracking management quality.

Developed models include entity-relationship diagram, use case diagram, context diagram, and data flow diagram. These models will certainly provide new knowledge, theories, and methods for the experts who will put these prints into action or implementation and other researchers who wish to seek facts relevant to purchase requests and financial tracking of government transactions.

It is recommended to utilize this design to develop the software in a purchase request and financial tracking in government agencies in the Philippines. This will eventually support and help them in their needs relevant to PRs. It is also recommended to consider adding PR Mapping; aside from tracking the PR through status, they could suggest adding the PR mapping to track the PR, upload other documents that require in their purchase request, and adding machine learning algorithms to predict the budget allocation of each office for the next incoming years.

\section{IMPLICATIONS}

The results of this paper will eventually be significant in the development of a purchase request system for different government agencies in the Philippines.

\section{ACKNOWLEDGEMENT}

The authors of this paper would like to express their gratitude to the significant people who were involved in conducting this scientific work.

\section{REFERENCES}

Baumgartner, D., Da Victoria LOBO, N., \& Carle, B. (2017). U.S. Patent No. WO2016029929A1 Disaster risk management and financing system, and corresponding method thereof. Washington, DC: U.S. Patent and Trademark Office.

Dennis, A., Wixom, B., \& Roth, R (2012). Process Modelling, System Analysis and Design, 5th ed. United States of America: John Wiley \& Sons, Inc.

Elmasri, R., \& Navathe, S. (2011). Fundamentals of Database Systems, 6th Edition. United States of America: Pearson. 
Espinoza, D., Iban, M., Torres, J., Villarama, P., Velasco, L., Comandao, A., Santos, W., \& Montaos, C. (2018). Project Amihan: Online Air Monitoring System for Selected Areas along McArthur Highway, Valenzuela City. International Journal of Computing Sciences Research, 2(1), 1-16. doi: 10.25147/ijcsr.2017.001.1.19

Jones, C. L., Sharpe, W. F., Scott, J. S., Watson, J. G., Maggioncalda, J. N., Bekaert, G., ... \& Park, R. T. (2000). U.S. Patent No. 6,021,397. Washington, DC: U.S. Patent and Trademark Office.

Jones, T.S. \& Richey, R.C (2000). Rapid prototyping methodology in action: A developmental study. Educational Technology Research and Development, 48, 63-68. doi: 10.1007/BF02313401

Jose, S. G. (2012). Preliminary examination of existing methodologies for allocating and tracking national government budget for disaster risk reduction (DRR) in the Philippines. Retrieved December 28, 2020, from https://www.undrr.org/publication/preliminary-examination-existingmethodologies-allocating-and-tracking-national-o.

Naidoo, B. (2010). Financial management in selected primary schools in Gauteng (Doctoral dissertation). UNISA Institutional Repository, University of South Africa, Pretoria, South Africa.

Office of Research University of Michigan Medical School. (2020). Research Procurement. Retrieved November 30, 2020, from https://research.medicine.umich.edu/ourunits/grant-services-analysis/post-award/research-procurement

Office of Technology Assessment (1984). Effects of Information Technology on Financial Services Systems. Washington, D. C.: U.S. Congress, Office of Technology Assessment, OTA-CIT-202.

Omoregbe, N. A., Azeta, A. A., \&Adewumi, A. (2014). Development Of A File Tracking System For Tertiary Institutions. In Proceedings of 6th international conference on education and New Learning Technologies (EDULEARN14). Spain. Retrieved from http://eprints.covenantuniversity.edu.ng/5567/1/1948.pdf

Ritchie, F. (2014). Resistance to change in government: Risk, inertia and incentives. (Working Papers 20141412). Department of Accounting, Economics and Finance, Bristol Business School, University of the West of England, Bristol. https://uwerepository.worktribe.com/OutputFile/807314

Salcedo, M. (2016). Methodology for Fast Processing of Purchase Requisitions, Elimination of Backlog and Improvement of Customer Service in Procurement Organizations. SSRN Electronic Journal. doi:10.2139/ssrn.2918601

Vicente, Ria S. (2008). Evaluation of the efficiency and effectiveness of the regional procurement service depots in the Philippines: A case of Region 1. Massey University, Albany, New Zealand. 


\section{Author's Biography}

Mark Van M. Buladaco is an instructor at Davao del Norte State College and is currently the Dean of the Institute of Computing. He earned a Bachelor of Science in Information Technology and Masters in Information Technology and is currently finishing his doctorate in Doctor of Business Management specialized in Information Systems. His research interest is in analyzing and designing information systems, data mining, artificial intelligence, and quantitative research on ICT.

Jennifer E. Sabugaa is a faculty of the Caraga State University. She is actively engaged and locked-in in all aspects of the entrepreneurship programs in the university through Navigatu. For the past two years, Jen guided the startups / incubatees and looked after them in their Incubation Program. She directly worked with the TBI Operations Team who was hired full time with the DOST-PCIEERD funded project. She attended various training from UC Berkeley's Sutardja Center for Entrepreneurship (SCET) through PhilDev's ISIP Program. 